\title{
Protocolo de avaliação clínica baseado em escore objetivo como preditor de sucesso de retalhos livres e reimplantes
}

Clinical evaluation protocol based on straightforward scoring as predictor of success of flee flaps and replantation

Protocolo de evaluación clínica basado en el score objetivo como predictor del éxito de colgajos libres y reimplantación Fernanda Ruiz de ANDRADE ${ }^{1}$

Rafael Barra Caiado FLEURY2

Aleixo Abreu TANURE ${ }^{2}$

Lauro TOFFOLO

Luis Guilherme Rosifini Alves REZENDE ${ }^{4}$

Alex Eduardo Calderón IRUSTA

Amanda Favaro CAGNOLATI ${ }^{4}$

Nilton MAZZER

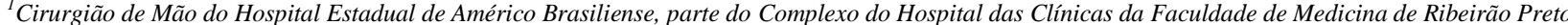
da Universidade de São Paulo (HC-FMRP-USP) 14051-140 Ribeirão Preto-SP, Brasil

${ }^{2}$ Cirurgião de Mão junto ao Programa de Cirurgia da Mão, Microcirurgia e Membro Superior do Hospital das Clínicas da Faculdade de Medicina de Ribeirão Preto da Universidade de São Paulo (HC-FMRP-USP)14051-140 Ribeirão Preto-SP, Brasil

${ }^{3}$ Cirurgião da Mão, Serviço de Ortopedia e Traumatologia do Hospital São Lucas da Pontifícia Universidade Católica do Rio Grande do Sul (PUCRS) $90610-000$ Porto Alegre - RS, Brasil

${ }^{4}$ Médico Assistente da Divisão de Cirurgia da Mão, Microcirurgia e Membro Superior do Hospital das Clínicas da Faculdade de Medicina de Ribeirão Preto da Universidade de São Paulo (HC-FMRP-USP) 14051-140 Ribeirão Preto-SP, Brasil

${ }^{5}$ Professor Titular e chefe do Serviço de Cirurgia da Mão, Microcirurgia e Membro Superior do Hospital das Clínicas da Faculdade de Medicina de Ribeirão Preto da Universidade de São Paulo (HC-FMRP-USP) 14051-140 Ribeirão Preto - SP, Brasil

\section{Resumo}

Os retalhos microcirúrgicos e reimplantes necessitam de cuidados específicos que devem ser realizados pelo cirurgião desde o momento da sua indicação, até os dias subsequentes à cirurgia. O trabalho em questão abordou à validação do protocolo utilizado pela equipe de um hospital terciário, desde o ano 2016. Os parâmetros clínicos (temperatura, cor, turgor, tempo de enchimento capilar e sangramento à perfuração) geraram um Escore que pode ser capaz de guiar a decisão do profissional, quanto à necessidade de uma reabordagem cirúrgica no período pós-operatório. Foram revisadas 55 tabelas de escores pós-cirúrgicos e correlacionados o escore obtido pelo paciente e o prognóstico da cirurgia, com o objetivo de definir valores de corte estatisticamente significativos para predição do sucesso da mesma, visando compreender à validade do protocolo em guiar a tomada de condutas. Foram determinados os valores de escores de 1 a 8 que definiram o grupo sem necessidade da intervenção cirúrgica; e aqueles superiores a 8 definiram o paciente com um risco de falha da cirurgia e necessidade da intervenção cirúrgica. Por não necessitar de procedimentos invasivos e exames de alta complexidade, o protocolo proposto torna-se uma eficiente ferramenta no diagnóstico precoce de um possível sofrimento vascular do procedimento microcirúrgico.

Descritores: Retalhos Cirúrgicos; Reimplante; Microcirurgia; Protocolo Clínico; Cuidados Pós-Operatórios; Exames Médicos.

\section{Abstract}

Microsurgical flaps and replantation require specific care by surgeons from indication to days following surgery. This study addressed the validation of the protocol used, since 2016, by a specialized hospital. Clinical parameters (e.g., temperature, color, turgor, capillary filling time, and bleeding at perforation) generated a score, which guided the professional's decision about the need for a surgical re-approach postoperatively. We reviewed 55 tables of postoperative scores and correlated each patient score with surgery prognosis. This method focused on defining statistically significant cutoff values to forecast surgery success and understanding the validity of this protocol in guiding the practices. Scores from 1 to 8 were assigned to patients with no need for surgical intervention, for scores above 8 , those with a risk of surgery failure and surgical intervention needs. As the proposed protocol requires neither invasive procedures nor high-complexity exams, it becomes an effective tool for early diagnosis of potential vascular damage by microsurgical procedures.

Descriptors: Surgical Flap; Replantation; Microsurgery; Clinical Protocols; Postoperative Care; Medical Examination.

\section{Resumen}

Objetivos: El objetivo del presente estudio fue informar el análisis del registro de un paciente sometido al tratamiento de una quemadura por Los colgajos microquirúrgicos y la reimplantación requieren atención específica por parte de los cirujanos desde la indicación hasta los días posteriores a la cirugía. Este estudio abordó la validación del protocolo utilizado, desde 2016, por un hospital especializado. Los parámetros clínicos (p. Ej., Temperatura, color, turgencia, tiempo de llenado capilar y sangrado en la perforación) generaron una puntuación, que guió la decisión del profesional sobre la necesidad de un nuevo abordaje quirúrgico después de la operación. Revisamos 55 tablas de puntajes postoperatorios y correlacionamos el puntaje de cada paciente con el pronóstico de la cirugía. Este método se centró en definir valores de corte estadísticamente significativos para pronosticar el éxito de la cirugía y comprender la validez de este protocolo para guiar las prácticas. Se asignaron puntuaciones del 1 al 8 a pacientes sin necesidad de intervención quirúrgica, para puntuaciones superiores a 8 , aquellos con riesgo de fracaso quirúrgico y necesidades de intervención quirúrgica. Como el protocolo propuesto no requiere procedimientos invasivos ni exámenes de alta complejidad, se convierte en una herramienta eficaz para el diagnóstico precoz del daño vascular potencial mediante procedimientos micro-quirúrgicos.

Descriptores: Colgajos Quirúrgicos; Reimplantación; Microcirugía; Protocolos Clínicos; Cuidados Posoperatorios; Exámenes Médicos.

\section{INTRODUÇÃO}

As transferências microcirúrgicas foram criadas e aperfeiçoadas desde a década de 60 e sua aplicação permitiu avanços importantes na área da cirurgia reconstrutiva ${ }^{1}$. Com os avanços atuais das técnicas microcirúrgicas, de novos instrumentos, da utilização do microscópio e a maior capacitação técnica dos cirurgiões, a taxa de sucesso reportada pode atingir 91 a $99 \%$.

Apesar desses avanços, os riscos de complicações associadas à anastomose vascular são uma realidade e podem levar à necessidade de uma reexploração cirúrgica de urgência ${ }^{2}$. A trombose no pedículo vascular constitui uma complicação frequente dos retalhos livres e dos reimplantes, ela independe da experiência do cirurgião ou do retalho escolhido. Isto acontece porque o tecido transferido é totalmente dependente do fluxo sanguíneo oriundo das anastomoses e, até que o processo de neoangiogênese se estabeleça no leito e na periferia da área receptora ${ }^{4}$, a trombose pode acontecer. Sabese que de 5 a $25 \%$ dos retalhos livres necessitam de reexploração devido ao comprometimento vascular ${ }^{4}$. 
O exame clínico pré-operatório constitui um fator importante para a predição das complicações. Entretanto, a maioria dos retalhos possuem sua indicação em situações agudas, o que não permite o preparo ideal e controle dos fatores que influenciam o prognóstico cirúrgico ${ }^{1}$.

A avaliação seriada pós-operatória é fundamental para o sucesso dos retalhos livres e dos reimplantes, frequentemente as anastomoses apresentam problemas - principalmente nos primeiros três dias ${ }^{3}$. Os parâmetros avaliados devem ser confiáveis, reprodutíveis, sensíveis, custo-efetivos e contínuos. A maioria dos microcirurgiões utiliza a avaliação dos critérios clínicos, como por exemplo: a cor do tecido transferido, temperatura, tempo de enchimento capilar e perfurações ${ }^{1,4,5}$. O sucesso do retalho livre, em última análise, depende da habilidade do avaliador em identificar precocemente quando um retalho está em sofrimento, visto que a chance de sucesso de uma exploração secundária é inversamente proporcional ao tempo do sofrimento do tecido ${ }^{2-5}$.

A maioria das séries na literatura recomenda avaliação do caso a cada uma hora nas primeiras 24 a 48 horas pós-operatórias ${ }^{4}$. Dentre as principais complicações existentes estão a trombose arterial e a trombose venosa. A trombose arterial deve ser considerada caso o retalho encontra-se pálido, frio ao toque, sem sangramento à perfuração e sem enchimento capilar $^{6}$ (ou tempo superior a três segundos). A trombose venosa por sua vez, apresenta-se clinicamente com cianose e sangramento de coloração escura à perfuração ${ }^{6}$.

Outros métodos de avaliação podem ser utilizados, como Doppler externo, Doppler implantável ${ }^{1,5}$, oximetria de pulso (em reimplantes de dedos, por exemplo) ${ }^{3,4}$, medida do $\mathrm{pH}$ do tecido, e até mesmo PET-CT ${ }^{5}$, todavia geram aumento dos custos médico-hospitalares por serem tecnologias relativamente recentes e com alta especificidade. A maior complicação das anastomoses é sem dúvida a trombose venosa, seguida da trombose arterial, dentro das primeiras 48 horas. Apesar dos métodos de avaliação, qualquer dúvida quanto à viabilidade do retalho deverá levar o cirurgião a indicar a exploração do mesmo ${ }^{1,4}$.

Visto que a literatura enfatiza o uso de critérios subjetivos de avaliação pós-operatória dos retalhos livres, sujeitos a vieses entre observadores, e que a mesma conduta costuma ser adotada também em casos de reimplantes, é necessário propor uma maneira objetiva da avaliação, baseada em escores, com maior confiabilidade intra e interobservador, que permitem estabelecer o melhor momento para reintervenção cirúrgica do retalho ou do reimplante em sofrimento e sendo ela capaz de ser reproduzida em outros serviços especializados.

\section{MATERIAL E MÉTODO}

Trata-se de um estudo retrospectivo, baseado na revisão das tabelas de escore dos retalhos livres e reimplantes, preenchidas e anexadas aos prontuários. A população estudada foi de pacientes operados em um hospital terciário, submetidos à retalhos livres e reimplantes, e avaliados conforme o protocolo adotado pela instituição.

Foram incluídos os 49 pacientes operados entre 01 de março de 2016 e 01 de agosto de 2018, que tiveram os formulários devidamente preenchidos pela equipe assistente durante as primeiras 72 horas do pós-operatório. Aqueles que sofreram uma nova intervenção cirúrgica continuaram sendo avaliados até o total de 72 horas, contadas a partir da primeira cirurgia, mantendo a mesma proposta do protocolo.

Foram observados e correlacionados o escore obtido pelo paciente e o prognóstico da cirurgia, com o objetivo de definir valores de corte estatisticamente significativos para a predição do sucesso da cirurgia, visando compreender a validade do protocolo em guiar a tomada de condutas. Os pacientes foram divididos em três grupos, sendo eles: Grupo 1 pacientes sem necessidade de reabordagem; Grupo 2 - pacientes que precisaram de reabordagem de emergência, e tiveram sucesso; e Grupo 3 - pacientes que não tiveram sucesso após reabordagem de emergência. Para análise estatística, foi utilizado o teste não paramétrico de Kruscal-Wallis para comparação dos escores de cada grupo, com a estimativa dos limites superior e inferior de cada grupo por meio dos percentis $2,5 \%$ e $97,5 \%$. Desta forma podemos indicar os limites considerando que 95\% dos dados estarão enquadrados nos mesmos. Todas as análises foram realizadas com o uso do pacote agricolae do software R Core Team, $2017^{7}$.

O objetivo deste estudo foi o estabelecimento das três áreas de corte que ajudarão o profissional a tomar a conduta adequada: escore verde - sem necessidade de reabordagem/bom prognóstico; escore amarelo - intervenção cirúrgica se manutenção do escore ou piora; escore vermelho - reintervenção imediata.

O Protocolo de Avaliação dos Retalhos Microcirúrgicos e dos Reimplantes objetiva a padronização das medidas clínicas e da avaliação seriada dos pacientes submetidos a esses tipos de procedimentos cirúrgicos.

A aplicação do referido protocolo é iniciada imediatamente após o término do procedimento cirúrgico através de cuidados específicos e da prescrição médica direcionada. Sendo assim, o paciente deverá ser mantido na sala de recuperação anestésica durante as primeiras 24 horas, em monitorização multiparamétrica. A pressão arterial deverá ser mantida com a média (PAM) aproximada $>70$, e mantendo o jejum. 
A área operada deve ser mantida aquecida com foco de luz incandescente ou com ar aquecido, o membro posicionado ao mesmo nível do corpo, e o curativo frouxamente aplicado com uma janela para observação. A prescrição médica deverá conter hidratação venosa rigorosa, analgesia e ansiolíticos. É preconizado pelo serviço a anticoagulação pósoperatória, com Heparina não-fracionada subcutânea a cada oito horas.

A observação clínica respeitou a seguinte cronologia no pós-operatório: avaliação a cada 1 hora nas primeiras 24 horas; a cada 2 horas entre 24 e 48 horas; a cada 4 horas entre 48 e 72 horas; e a cada 6 horas após as 72 horas de pós-operatório até a alta hospitalar. Em cada exame clínico, uma tabela de escore, proposta pelo Serviço de Cirurgia da Mão, Microcirurgia e Membro Superior do Hospital das Clínicas da Faculdade de Medicina de Ribeirão Preto da Universidade de São Paulo (HC-FMRP-USP) foi preenchida levando em consideração quatro critérios: a cor, o tempo de enchimento capilar, o turgor e a temperatura. Cada item gerou um escore que, somados, resultou em um escore final. Apenas em caso de dúvida sobre a viabilidade do retalho/reimplante, o avaliador poderá realizar perfurações e observar o sangramento da extremidade, aplicando também o mesmo escore, somando-o ao valor dos demais critérios, conforme exemplificado na Figura 1. Se a avaliação seriada apresentar valores crescentes do escore, a reexploração cirúrgica está indicada.

\begin{tabular}{|c|c|c|c|c|c|c|c|}
\hline \multirow[t]{3}{*}{ Avaliador } & Temperatura & Cor & Turgor & Perfusão & Perfuração & Fotografia & Escore \\
\hline & Quente $=0$ pts & Rosado $=0$ & Normal $=1 \mathrm{pt}$ & $1-3 s=0$ & Vermelho $=0$ & & \\
\hline & Frio $=5 \mathrm{pts}$ & Moteado $=1 \mathrm{pt}$ & Tenso $=2$ pts & $<1 \mathrm{~s}=2 \mathrm{pts}$ & Escuro $=2 \mathrm{pts}$ & \multicolumn{2}{|c|}{ Observaçỗes } \\
\hline \multirow[t]{2}{*}{ Hora } & & Azulado $=2$ pts & Nenhum $=3 \mathrm{pts}$ & $>3 \mathrm{~s}=4 \mathrm{pts}$ & Sem sangramento $=3 \mathrm{pts}$ & & \\
\hline & & Branco $=3 \mathrm{pts}$ & & Nenhum $=5 \mathrm{pts}$ & & & \\
\hline
\end{tabular}

Figura 1: Modelo de tabela de escore

Fonte: Serviço de Cirurgia da Mão, Microcirurgia e Membro Superior do Hospital das Clínicas da Faculdade de Medicina de Ribeirão Preto da Universidade de São Paulo (HC-FMRP-USP)

\section{RESULTADOS}

O trabalho incluiu 49 pacientes operados no período citado, sendo 43 homens e seis mulheres. Foram selecionados 31 retalhos e 24 reimplantes, com o total de 55 tabelas de escore devidamente preenchidas nas primeiras 72 horas de pós-operatório. Dois pacientes foram submetidos a um novo retalho devido ao insucesso do primeiro procedimento cirúrgico, e estas cirurgias foram analisadas separadamente.

No caso de reimplante de múltiplos dedos, estes foram pontuados individualmente, gerando um escore separado para cada dedo reimplantado. Vinte e sete pacientes tiveram boa evolução no pósoperatório imediato, sem necessidade de nenhuma intervenção no período, preenchendo o Grupo 1 . Doze formaram o Grupo 2, pois apresentaram sinais de sofrimento vascular e retornaram ao centro cirúrgico para exploração da anastomose, com melhora dos parâmetros após a intervenção.
Finalmente, 16 pacientes foram reabordados devido piora clínica do retalho ou reimplante, mas não tiveram sucesso apesar da intervenção, com perda completa da cirurgia - caracterizando o Grupo 3.

Na Tabela 1 são apresentados os resultados da estatística descritiva (média, mediana, desvio padrão, valores mínimo e máximo) dos escores dos grupos avaliados. O teste de Kruscal-Wallis $(\mathrm{p}<0,05)$ indica que existe diferença nos escores entre o grupo 1 e os demais, não sendo observadas diferenças significativas entre os Grupos 2 e 3.

Tabela 1. Análise estatística descritiva dos escores dos grupos avaliados \begin{tabular}{l|c|c|c|c|c|c|c|c}
\hline & Média & Mediana & Rank & DP & Min & Máx & LI & LS \\
\hline Grupo 1 & 2,09 & 1 & 372,8 B & 1,81 & 1 & 11 & 1 & 8
\end{tabular}

\begin{tabular}{l|l|l|l|l|l|l|l|l}
\hline Grupo 2 & 7,35 & 8 & $697,26 \mathrm{~A}$ & 3,31 & 2 & 15 & 2,4 & 13,4 \\
\hline
\end{tabular}
\begin{tabular}{c|c|c|c|c|c|c|c|c|}
\hline Grupo 3 & 12,62 & 12,5 & 763,75 A & 2,8 & 8 & 18 & 8,375 & 17,625 \\
\hline
\end{tabular} $\mathrm{DP}=$ desvio padrão; Min = mínimo escore do grupo; Max = máximo escore do grupo; LI = Limite inferior para a normalidade dos dados; LS=Limite superior Posições de rank seguidas pela mesma letra não diferem entre si pelo teste de Kruscal-Wallis a 95\% de confiança (Fonte: Dados da Pesquisa)

Ao avaliar os limites inferior e superior (valores de normalidade) para os grupos, no qual 95\% dos escores se encontram, observa-se que os limites do Grupo 2 se sobrepõem aos Grupos 1 e 3. Por outro lado, os limites dos Grupos 1 e 3 não apresentam esta sobreposição. Ao analisar conjuntamente os limites obtidos e o teste de Kruscal-Wallis, observa-se que há uma diferença clara entre os grupos 1 e 3 , demonstrando que a metodologia empregada pode ser utilizada para definir estes dois grupos. Desta maneira, determinase que, o intervalo de escore de 1 a 8 define o Grupo 1 (escore verde) - sem necessidade de intervenção; e aquele superior a 8 (escore vermelho) define o paciente em risco de falha da cirurgia e necessidade de intervenção cirúrgica imediata (Figura 2).

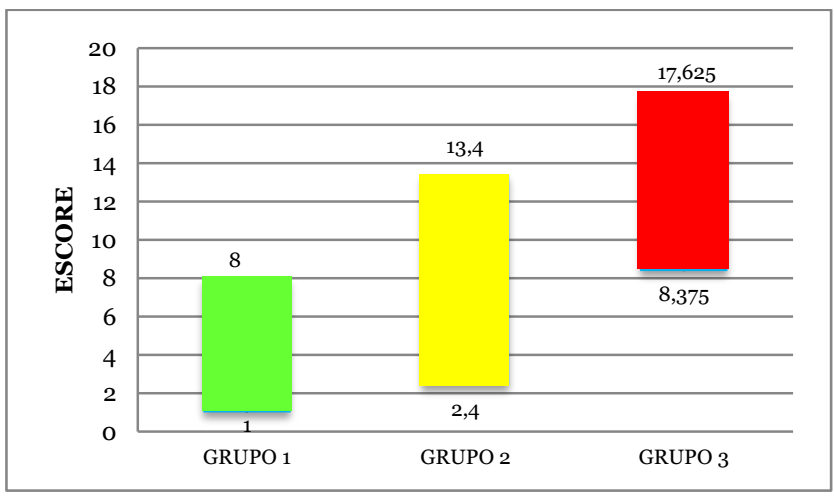

Figura 2: Limites inferior e superior dos grupos estudados. Fonte: Dados da Pesquisa

\section{DISCUSSÃO}

Sabe-se que a monitorização rigorosa e revisão cirúrgica precoce podem salvar uma anastomose microvascular em $43 \%$ a $89 \%$ dos casos ${ }^{8}$. Em revisão sistemática publicada em 2015, Chae $^{9}$ defende que apesar de existirem estudos que demonstram que outros métodos de avaliação pósoperatória podem determinar comprometimento da anastomose de maneira mais precoce, isto curiosamente não aumentou as taxas de sucesso das 
cirurgias. Considerando o cenário da saúde pública no Brasil, com dificuldades financeiras e assistenciais, o protocolo avaliado constitui ferramenta útil devido sua facilidade de aplicação e ausência de custos adicionais ao atendimento dos pacientes.

Hidalgo e Jones $^{10}$ revisaram 150 retalhos livres consecutivos; aqueles que apresentaram sofrimento vascular foram reexplorados, em média, 1,5 horas após a monitorização, com sucesso em 90 a $98 \%$ destes.

Bigdeli $^{8}$ concluiu em seu trabalho que a monitorização pós-operatória deve ser mais cuidadosa e frequente nos três primeiros dias, assim como pode ser benéfica a manutenção dos cuidados até o sétimo dia, em retalhos que são essenciais à vida ou ao bem-estar do paciente. O Protocolo apresentado neste estudo mostrou um formato semelhante, com aplicação do escore até o dia da alta hospitalar.

Relatos na literatura que propõem métodos objetivos de classificação e estadiamento destas cirurgias são escassos. Giunta ${ }^{11}$ propôs a avaliação da cor, tempo de enchimento capilar e, em casos de dúvida, perfuração para observação do sangramento, pelas primeiras 48 horas. Os dados foram tabelados e classificados em 4 estágios para complicações arteriais e 4 estágios para complicações venosas. Nesta classificação a intervenção foi proposta entre os estágios 1 e 3 , visto que o estágio 4 caracteriza-se por lesão irreversível da microvasculatura para os dois grupos ${ }^{11}$. Isto se assemelha em parte ao escore proposto neste trabalho, visto que propõe janela de oportunidade ampla para o cirurgião agir antes de atingir o estágio final.

Neste trabalho, o protocolo avaliado considerou os critérios clínicos consagrados na prática médica, e os transformou em valores numéricos. Isto permitiu uma maior facilidade na interpretação da evolução e do prognóstico cirúrgico, bem como na transmissão das informações entre os membros da equipe envolvida. Com a análise dos escores obtidos para cada grupo, o objetivo foi criar 3 zonas de segurança e janela de oportunidade para reintervenção. Entretanto, o Grupo 2 apresentou uma sobreposição aos Grupos 1 e 3, o que não permitiu a definição do escore intermediário - no qual a intervenção deveria ser imediata e com grande chance de sucesso.

Com isso, este protocolo foi capaz de estabelecer apenas o escore de corte no qual os retalhos e reimplantes provavelmente passaram do período ideal de intervenção, com maior chance de perda. Desta maneira o cirurgião deverá se atentar a este detalhe e efetuar todas as medidas possíveis, antes que o escore chegue ao valor de corte - igual ou maior que 9 .

É importante atentar que a análise estatística se limitou as primeiras 72 horas após a cirurgia, e os grupos estudados apresentaram intervenções e perdas após este período. O uso dos resultados obtidos neste estudo nos possibilitará avaliar a aplicabilidade dos valores encontrados durante a monitorização tardia em análises futuras.

\section{CONCLUSÃO}

Com base na metodologia mepregada e nos resultados obtidos concluiu-se que o Protocolo de Avaliação dos Retalhos Livres e Reimplantes proposto foi capaz de auxiliar o microcirurgião a identificar sinais clínicos das complicações vasculares, e quantificá-los através do escore numérico. Ademais, valores superiores a 8 sugerem que a intervenção se encontra em caráter tardio, com um risco aumentado de insucesso cirúrgico. A utilização do referido protocolo permitiu à avaliação simplificada, de fácil acesso, compreensão e aplicação por toda a equipe assistente, bem como a transmissão das informações de maneira eficiente e padronizada; não utilizando dispositivos tecnológicos, não houve custos adicionais ao tratamento, uma grande vantagem em serviços públicos de saúde no qual o acesso à recursos financeiros é escasso.

\section{REFERENCIAS}

1. Roehl KR, Mahabir RC. A practical guide to free tissue transfer. Plast Reconstr Surg. 2013; 132(1):147-58.

2. Bui DT, Cordeiro PG, Hu QY, Disa JJ, Pusic A, Mehrara BJ. Free flap reexploration: indications, treatment, and outcomes in 1193 free flaps. Plast Reconstr Surg. 2007;119(7):2092-100.

3. Saint-Cyr M, Wong C, Buchel EW. Free tissue transfers and replantation. Plast Reconstr Surg. 2012;130(6):858-78.

4. Salgado CJ, Moran SL, Mardini S. Flap monitoring and patient management. Plast Reconstr Surg. 2009;124(6 Suppl):295-302.

5. Cervenka B, Bewley AF. Free flap monitoring: a review of the recent literature. Curr Opin Otolaryngol Head Neck Surg. 2015;23(5):393-98.

6. Korompilias AV, Lykissas MG, Vekris MD, Beris $\mathrm{AE}$, Soucacos PN. Microsurgery for lower extremity injuries. Injury. 2008;39(Suppl):S103-8.

7. R Core Team. R: A language and environment for statistical computing. R Foundation for Statistical Computing, Vienna, Austria, 2017. Disponível em: https://www.R-project.org/. Acesso em: 01 jan 2019.

8. Bigdeli AK, Gazyakan E, Schmidt VJ. Long-term outcome after successful lower extremity free flap salvage. J Reconstr Microsurg. 2018;1:1-82.

9. Chae MP, Rozen WM, Whitaker IS. Current evidence for postoperative monitoring of microvascular free flaps: a systematic review. Ann Plast Surg. 2015;74(5):621-32. 
10. Hidalgo DA, Jones CS. The role of emergent exploration in free-tissue transfer: a review of 150 consecutive cases. Plast Reconstr Surg. 1990;86(3):499-501.

11. Giunta R, Geisweid A, Feller AM. Clinical classification of free-flap perfusion complications. J Reconstr Microsurg. 2001;17(5):341-45.

\section{CONFLITO DE INTERESSES}

Os autores declaram não haver conflitos de interesse.

\section{AUTOR PARA CORRESPONDÊNCIA}

Fernanda Ruiz de Andrade

fernandaruiz90@hotmail.com

Submetido em 31/12/2019

Aceito em 11/01/2020 